\title{
Soft Sensing of Melt Temperature in Polymer Extrusion
}

\section{Document Version}

Accepted author manuscript

Link to publication record in Manchester Research Explorer

\section{Citation for published version (APA):}

Abeykoon, C. (2016). Soft Sensing of Melt Temperature in Polymer Extrusion. In 2016 European Control Conference (ECC)

\section{Published in:}

2016 European Control Conference (ECC)

\section{Citing this paper}

Please note that where the full-text provided on Manchester Research Explorer is the Author Accepted Manuscript or Proof version this may differ from the final Published version. If citing, it is advised that you check and use the publisher's definitive version.

\section{General rights}

Copyright and moral rights for the publications made accessible in the Research Explorer are retained by the authors and/or other copyright owners and it is a condition of accessing publications that users recognise and abide by the legal requirements associated with these rights.

\section{Takedown policy}

If you believe that this document breaches copyright please refer to the University of Manchester's Takedown Procedures [http://man.ac.uk/04Y6Bo] or contact uml.scholarlycommunications@manchester.ac.uk providing relevant details, so we can investigate your claim.

\section{OPEN ACCESS}




\title{
Soft Sensing of Melt Temperature in Polymer Extrusion
}

\author{
Chamil Abeykoon
}

\begin{abstract}
Precise monitoring techniques are invaluable to any process for diagnosing its operational health, safety concerns and also for achieving good process control. In polymer extrusion, it is quite difficult to visually observe the melt inside barrel during the process operation and hence the level of control of the process operational quality is highly dependent upon the process monitoring techniques. Currently, a number of physical sensing devices are widely available in industry for monitoring of parameters such as melt temperature, melt pressure, screw speed and so forth. However, there are some limitations to use physical sensors in process measurements due to several constraints such as their access requirements, disruptive effects on the melt flow, fragility, complexity, etc. Thus, the application of soft sensing techniques should be highly useful for improved process monitoring and hence for advanced process control. In this work, a general discussion is made on the soft sensors and soft sensing applications in polymer extrusion. Then, a soft sensor concept is proposed for the die melt temperature profile prediction in polymer extrusion. The simulation results showed that the proposed technique can predict the temperature profile across the melt flow in real-time with good accuracy. Eventually, the importance of developing of such soft sensing techniques is discussed while providing some of the possible directions for future research.
\end{abstract}

Index Terms-Polymer extrusion, Process monitoring, Infrared sensor, Soft sensor, Melt temperature profile, Modelling.

\section{INTRODUCTION}

Polymer extrusion is a fundamental technique of processing of polymeric materials and is involved in the production of various commodities in the diverse industrial sectors. Since materials are processed inside a closed barrel, process monitoring techniques are highly important in determining the process health and also for ensuring the process safety. Basically, the melt pressure and temperature (i.e., point or bulk measurements) monitoring techniques are wellestablished in industrial applications and these are used as the major measures of determining the process functional quality and the quality of the melt output. Obviously, the melt pressure is a good indication on process functional quality and the variations of melt pressure would result in fluctuations in melt temperature and process output rate. However, the commonly used melt temperature sensors are flush mounted to the barrel wall and also they are highly affected by the barrel wall set temperature. Moreover, they are not capable of measuring a melt temperature profile or detecting rapid variations in melt temperature [1], [2]. Melt temperature profile measurements are highly difficult in industry as it disturbs the smooth motion of the melt flow and also due to the factors such as access requirements, complexity, fragility

Chamil Abeykoon is with the Faculty of Engineering and Physical Sciences of the University of Manchester, Oxford Road, Manchester, M13 9PL, UK, E-mail: chamil.abeykoon@manchester.ac.uk, Tel: +441613062540 of the sensors, etc. Currently, no technique is available for making melt temperature profile measurements in industry. Furthermore, the melt viscosity (which is another important process parameter of indicating the melt quality) is also not possible to directly measure by using a physical sensor. The in-line rheometers, a common method of making viscosity measurements, are also not industrially attractive due to their possible disruptions on the steadiness and rate of the melt flow. Therefore, soft sensors and soft sensing should be highly invaluable for a process like polymer extrusion as it has a number of parameters which are difficult to directly monitor by a physical sensor. More details on the process operation and mechanisms of polymer extrusion can be found in the literature [2], [3].

\section{A. Soft sensor}

A soft sensor, a virtual sensor or an inferential estimator is a technique of estimating some particular parameter/s (e.g., quality measures, functional variables) in various applications when a hardware sensor is unavailable or unsuitable. Moreover, soft sensors are used in real-time process monitoring and control; fault detection; process diagnostics; etc. Currently, soft sensors are widely used in chemical processes such as reactors, distillation columns, cement kilns, food processing, paper and pulp industry, etc, to estimate the product quality parameters [4]. In the majority of these previous soft sensing applications, the non-linear behaviours of the industrial processes have been modelled with the techniques such as artificial neural network (ANN); fuzzy systems; partial least squares (PLS); support vector machine (SVM) and support vector regression (SVR) and some of these are discussed in the next section. Currently, soft sensors are becoming widely popular in various industrial applications due to their advantages such as:

- It can be highly useful in the applications where physical sensors may not be applicable or unsuitable.

- It offers real-time estimations while handling time delays. - It is a low cost alternative for expensive online analysers. - It can be easily implemented on the existing hardware platform and no additional investment may be required.

However, a few barriers/complexities are also attributed to the design/application of the soft sensors:

- It requires a considerable process expert knowledge, effort and time to design.

- Its performance depends on the quality of the training/validation data (may have problems due to outliers, noise and missing data).

- It may be specific only for a given machine, material or processing conditions. 
Obviously, the expert knowledge is playing a key role in the design and application of a soft sensor. The designer should have a sound knowledge in the areas such as process monitoring; data collection/processing; modelling and model training/validation; soft sensor design/adaptation/maintenance; etc. In the long run, the drifts of the process may be a major problem on the performance of the soft sensor and hence it should be compensated either by adapting or re-developing the model/s [5]. Therefore, designing and maintaining of a soft sensor is an extensive task and more details relating to this area can be found in the literature [4], [6], [7].

\section{B. Inferential process monitoring in polymer extrusion}

Although some of the key process parameters such as melt viscosity and temperature profile across the die melt flow are difficult to measure/monitor using physical sensors only a few previous work has been reported so far on inferential prediction of such parameters in polymer extrusion.

A previous work by the author [8], [9] made an attempt to predict the process thermal stability inferentially. Correlations between the screw load torque, melt pressure and melt temperature fluctuations were examined by analyzing experimentally measured signals. However, no strong correlations between these signals could be observed. It was found that the screw load torque signal is not sensitive enough to identify unstable melting issues as it is dominated by the solids conveying torque. However, melt pressure fluctuations had slight correlations with melt temperature fluctuations particularly at low screw speeds. Nevertheless, none of these signals showed sufficiently good performance for them to be used as a powerful tool of monitoring the process thermal stability inferentially. To the author's knowledge, there is no other reported work in the literature on inferential thermal monitoring in polymer extrusion.

Wang et al. [10] used a soft sensing approach for making online measurements of the degree of orientation of polymer materials incorporating ultrasonic velocity measurements and infrared spectroscopy. The relationship between the ultrasonic velocity and the degree of orientation were established based on a SVM approach. The authors mentioned that the soft sensing system was able to make accurate measurements with a relative error of around 5\%.

Chitralekha and Shah [11] proposed a steady-state melt flow index soft sensor for an industrial scale polymer extrusion process by using a SVR approach. The authors claimed that the SVR-based soft sensor was valid over a wide range of melt indices and outperformed the existing nonlinear leastsquare-based soft sensor in terms of lower prediction errors. Furthermore, they mentioned that the proposed technique is having a few tuning parameters (compared to neural network approaches) and good generalization capabilities over other nonlinear black-box modelling techniques.

Gonzaga et al. [12] developed a soft sensor for viscosity prediction of a polyethylene terephthalata (PET) production process. The soft sensor which was based on a feed-forward artificial neural network performed its predictions with a relative error of approximately $0.3 \%$. Then, the sensor was integrated with an industrial process control system through a supervisory system and the authors mentioned that the controller gave good performance by allowing an effective and feasible operation of the PET production plant.

Sharmin et al. [13] designed a PLS based soft sensor to predict the melt flow index of polymeric materials. In the development of the PLS model, 48 process variables and the corresponding time delays were considered. The sensor was implemented on an industrial reactor and the authors claimed that the successful results were achieved. Moreover, they have discussed about the difficulties associated with the data-driven modelling of industrial data.

McAfee et al. [14] proposed a soft sensor which consists of two models to estimate the melt viscosity. The first model predicts the viscosity based on the processing conditions while the second model predicts the pressure based on the estimated viscosity. The estimated pressure is compared with the actual die pressure and the error signal is used to compensate for errors in the viscosity prediction model. A grey box modelling technique was used to develop dynamic models and the sensor gave predictions within $2 \%$ error.

Shi and Liu [15] proposed a melt index (MI) prediction soft sensor for a polypropylene (PP) polymerization process. The model included in the soft sensor was developed by a weighted least squares support vector machines (weighted LS-SVM) approach and it predicts the MI based on nine input process variables. Moreover, this model predicted the MI with a mean relative error (MRE) of approximately $3.27 \%$ and outperformed the accuracy of the sensors based on LS-SVM and SVM approaches. In other work by $\mathrm{Li}$ and Liu [16], a MI soft senor was proposed for the same polymerization process based on a radial basis function (RBF) neural network incorporating an adaptive ant colony optimization algorithm. As was mentioned by the authors, this sensor was able to predict the MI with an MRE of $0.44 \%$ which was superior in performance to their previous work.

Ogawa et al. [17] proposed a MI sensor for an industrial high density polyethylene process using a few on-line measurements. In general, two models were used in the inferential MI measurement system: (i) an MI model which presents the relationship between the process variables and the MI (ii) a cumulative model that describes the relationship between the MI of the total polymer in the reactor. The soft sensor was combined with a model predictive controller which was aiming at the process quality control. The authors claimed that the controller with the MI soft sensor performed well with less quality deviation but they are still undertaking trials prior to its application in industrial processes.

Few other work [5], [18]-[21] also attempted to inferentially predict some process parameters in polymer extrusion.

\section{A SOFT SENSOR FOR DIE MELT TEMPERATURE PROFILE PREDICTION IN POLYMER EXTRUSION}

\section{A. Background}

Melt thermal homogeneity/stability is a key requirement in polymer processing and hence the melt temperature is a commonly measured parameter in polymer processes. 
Currently, a number of point/bulk measurement techniques are well-established in the industrial applications while a few thermal profile measurement techniques have been attempted in research. More details on these existing thermal measurement techniques in polymer processing were previously discussed by the author [3], [22], [23]. As was revealed by the previous work [3], [8], [22]-[25], temperatures at the different radial locations of the extruder output melt flow are significantly different and also these variations are dependent upon processing conditions, material being processed and the machine geometry. Obviously, point/bulk thermal measurement techniques are not capable of detecting these thermal variations across the melt flow although these are widely used in the current industrial applications. Hence, the melt temperature profile measurement is highly suitable for determining the actual thermal homogeneity/stability across the extruder output melt flow. Some of the measurement techniques in research (e.g., a thermocouple mesh [26], [27], a fluorescence technique [28]) are capable of measuring a temperature profile across the melt flow but these techniques are not yet suitable for use in a production environment due to constraints such as their complexity, limited durability, access requirements, disruptiveness on the melt flow and output, etc. Hence, it is clear that the physical sensors are not suitable for making die melt temperature profile measurements in practice and also a soft sensing technique is not yet available for this purpose. Thus, a novel approach for developing a temperature profile prediction (across the extruder die melt flow) soft sensor is presented in this study.

\section{B. Concept}

From the previous thermal monitoring studies [3], [22], [23], it has been realized that a thermocouple mesh technique [26], [27] is good in providing detailed and accurate information on the thermal homogeneity of the extruder output melt flow. Therefore, it was felt that it is better if it is possible to inferentially predict the melt temperatures at different melt flow radial locations to obtain similar types of measurements to the thermocouple mesh. In fact, thermocouple mesh technique can be used to collect experimental data and then the data can be used to develop a dynamic model to predict the melt temperature profiles across the melt flow during the process operation (i.e., in real-time). Although such a model can predict the melt temperature profile, it is still good to have some reference or correction for the predicted melt temperatures at the different radial locations to ensure the prediction accuracy. From the experimental results achieved by evaluating the commonly used melt temperature sensors in polymer processing [3], [23], it was found that an Infrared (IR) temperature sensor follows the process thermal dynamics in a similar way to the thermocouple mesh better than the other temperature sensors which were used in the evaluation. Specifically, it is not required to add any modification to the existing extruders to use an IR temperature sensor as it can be attached to a standard sensor port which is designed to attach typical temperature/pressure sensors. Moreover, the non-invasive melt temperature measurements with a fast response time can be made by using IR sensors near to the screw tip or in the die during the process operation and hence it is industrially compatible. Therefore, an IR temperature sensor should be good to obtain a temperature feedback to correct the possible errors of the soft sensor's temperature predictions at the different melt flow radial positions.

\section{Process investigation}

Prior to designing a soft sensor, it is essential to understand the basic process mechanisms and functional principles while identifying the key process variables. To obtain the required background knowledge, a large number of experiments were performed on industrial scale extruders using industrially common polymeric materials and processing conditions, and a detailed review of the literature was also carried out.

\section{Selection of the key process variables, model structure and modelling technique}

It was planned to use two dynamic models within the novel temperature profile prediction soft sensor. One model is to predict the melt temperature at the different radial positions of the melt flow (i.e., the $T_{P}$ model) and the other is to predict the melt temperature given by an IR temperature sensor (i.e., the $T_{I R}$ or feedback model). From the details gathered, it was realized that the melt temperature of a given point across the melt flow which is $j \mathrm{~mm}$ away from the melt flow centre $\left(T_{m, j}\right)$ can be modelled as a function of screw speed $\left(\omega_{s c}\right)$, barrel set temperatures $\left(T_{b}\right.$, subscript $b$ represents a number of barrel set temperature zones: $\left.T_{1}, T_{2}, \cdots, T_{n}\right)$ and die radial position $\left(R_{p, j}\right)$ :

$$
T_{m, j}=f\left(\omega_{s c}, R_{p, j}, T_{b}\right)
$$

Previous studies have shown that the die melt temperature profile is dependent upon a number of processing, material and machine parameters [8], [22], [24], [25], [29]. However, the three variables given in Eq. (1) were identified as the major influential variables to the die melt temperature profile for a given machine and a material, and hence these were selected to use as inputs to the $T_{P}$ model. At this stage, the soft sensor is proposed for a given machine and a material (as this is the first approach of its kind) and then in future, it can be generalized for other machines and materials as well.

Based on the experimental observations, the melt temperature measured by an IR temperature sensor $\left(T_{I R}\right)$ can be represented as a function of $\omega_{s c}, T_{m, a c t}$ and $T_{b}$ :

$$
T_{I R}=f\left(\omega_{s c}, T_{m, a c t}, T_{b}\right)
$$

The $T_{m, a c t}$ is the mean value of the predicted melt temperatures at the different radial positions by the $T_{P}$ model. Then, the difference between the predicted and measured IR temperature measurements $\left(T_{I R, E \text { rror }}\right)$ is given by:

$$
T_{I R, \text { Error }}=T_{I R}-\hat{T}_{I R}
$$

where $\hat{T}_{I R}$ is the predicted melt temperature relating to the IR temperature sensor.

The selection of an appropriate modelling technique is the next step after choosing the key process variables and the structures of the models. A few important factors should be considered for making this choice as the developed models: 
- should be simple and compact (i.e., less computational complexity).

- should be compatible for using in real-time applications.

- should take the corresponding process delays into account.

- should predict the corresponding variable/s with an acceptable accuracy over the full process operating window.

After considering a number of possible techniques, a twostage algorithm which can be used to develop simple and compact linear/nonlinear polynomial models with a linearin-the-parameters (LITP) structure was chosen to develop the models. The functions given in Eqs. (1) and (2) can be modelled as a general nonlinear discrete-time dynamic multiinput-single-output (MISO) system as given by Eq (4):

$$
\begin{aligned}
y(t)= & f\left(y(t-1), y(t-2), \ldots y\left(t-n_{1}\right), \ldots y\left(t-n_{a}\right), u_{i}\left(t-n_{i k}\right),\right. \\
& \left.u_{i}\left(t-n_{i k}-1\right), \ldots u_{i}\left(t-n_{i k}-n_{1}\right), \ldots u_{i}\left(t-n_{i k}-n_{i b}\right)\right)(4)
\end{aligned}
$$

where $y(t)$ is the system output at time $t, u_{i}(t), i=1, \cdots, m$ are the system inputs at time $t$ ( $m$ is the total number of inputs to the system), $n_{a}$ is the number of poles, $n_{i b}$ is the number of zeros plus 1 and $n_{i k}$ is the corresponding delays (i.e., the number of input samples that occur before each input affects the output) of each input. More details on the modelling technique is not provided as the author has used the same technique for modelling of the melt pressure [30], melt temperature [24], [25], [31], and power consumption [32] in polymer extrusion where good results were achieved.

\section{EQuipment, Procedure \& MAterials}

All measurements were carried out on a medium scale industrial extruder. Melt temperature profiles at the $38 \mathrm{~mm}$ diameter die were measured using a thermocouple mesh with seven junctions which were placed across the die melt flow (distances from the die centreline to each mesh wire/junction: $0 \mathrm{~mm}, \pm 3.0 \mathrm{~mm}, \pm 4.5 \mathrm{~mm}, \pm 8.8 \mathrm{~mm}, \pm 11.0$ $\mathrm{mm}, \pm 14.7 \mathrm{~mm}, \pm 16.5 \mathrm{~mm}$, and $\pm 19.0 \mathrm{~mm}$ ). The die wall set temperature was used as the melt temperatures at the \pm 19 mm radial positions. As it was previously confirmed [29], the die melt temperature measurements are symmetrical across the centerline of the thermocouple mesh when averaged over sufficient time. Thus, the melt temperatures measured at these seven points across the die melt flow were mirrored over the die centreline to obtain the complete die melt temperature profile. The structure of the experimental set-up is shown in Figure 1. A data acquisition (DAQ) programme developed in LabVIEW was used to communicate between the experimental instruments and a PC. Screw speed and all temperature signals were acquired at $10 \mathrm{~Hz}$ sampling speed.

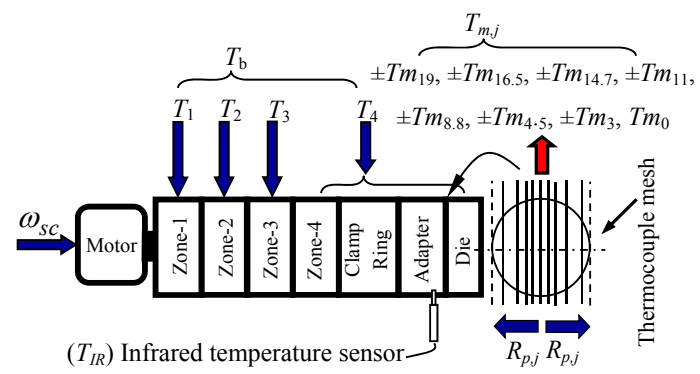

Fig. 1. A schematic of the experimental set-up
More details on the experimental set-up and procedure were discussed by the author previously [22], [24].

\section{A. Materials and experimental conditions}

Experimental trials were carried out on a virgin high density polyethylene (HDPE), (ExxonMobil HYA 800), (density: $0.961 \mathrm{~g} / \mathrm{cm}^{3}$, melt flow index (MFI): $0.7 \mathrm{~g} / 10 \mathrm{~min} @\left(190{ }^{\circ} \mathrm{C}\right.$, $2.16 \mathrm{~kg})$ ). The extruder barrel temperature settings were fixed as described in Table I under three different set conditions denoted as $\mathrm{A}$ (high temperature), $\mathrm{B}$ (medium temperature) and $\mathrm{C}$ (low temperature).

TABLE I

EXTRUDER BARREL TEMPERATURE SETTINGS

\begin{tabular}{|c|c|c|c|c|c|c|c|}
\hline \multirow{2}{*}{$\begin{array}{c}\text { Temperature } \\
\text { settings }\end{array}$} & \multicolumn{7}{|c|}{ Set temperatures $\left({ }^{\circ} \mathrm{C}\right)$} \\
\cline { 2 - 8 } Clamp ring & Adapter & \multirow{2}{*}{ Die } \\
\hline & 1 & 2 & 3 & 4 & & & \\
\hline A & 110 & 130 & 180 & 230 & 230 & 230 & 230 \\
\hline B & 105 & 125 & 175 & 215 & 215 & 215 & 215 \\
\hline C & 100 & 120 & 170 & 200 & 200 & 200 & 200 \\
\hline
\end{tabular}

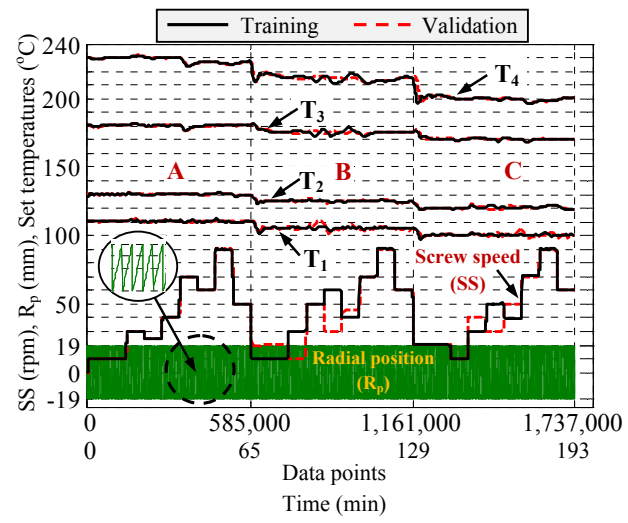

Fig. 2. The process settings matrices of training and validations tests

The experiments were started with the temperature setting A and data was recorded with the screw stationary for 1 minute. Then, the screw speed was increased up to 90 rpm with random steps of between $\pm 5-40 \mathrm{rpm}$ and in different barrel set temperatures with the extruder running for about 193 minutes continuously as shown in Figure 2. The extruder was allowed to stabilise for 15 minutes after each set temperature change while the extruder was hold for about 7 minutes at each other different condition. All of these settings were selected in order to generate realistic processing conditions whilst covering the full operating range of the extruder (i.e., 0-100 rpm). Separate tests were carried out to obtain the data for model training and validation.

\section{$B$. Model training and validation}

After studying a number of models, a $2^{\text {nd }}$ order model with six terms (i.e., with a $0.25 \%$ of normalized prediction error (NPE) on the validation data) and a $2^{\text {nd }}$ order model with fifteen terms (i.e., with a $1.22 \%$ of NPE on the validation data) were selected as the $T_{P}$ and $T_{I R}$ models, and these are given in Eqs. (6) and (5), respectively.

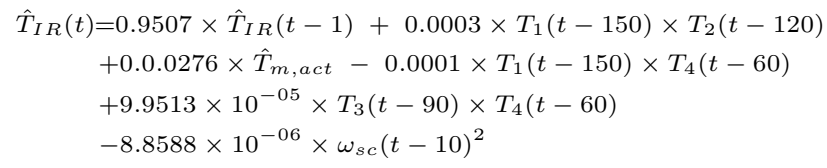




$$
\begin{aligned}
\hat{T}_{m, j}(t) & =0.8207 \times \hat{T}_{m, j}(t-1)-0.0012 \times \hat{T}_{m, j}(t-1) \times T_{2}(t-120) \\
& -0.0223 \times R_{p, j}(t)^{2}-0.0008 \times \hat{T}_{m, j}(t-1) \times \omega_{s c}(t-10) \\
& +0.0006 \times \omega_{s c}(t-10)^{2}+0.0081 \times R_{p, j}(t) \times T_{4}(t-60) \\
& +0.0638 \times T_{3}(t-90)-0.0037 \times \omega_{s c}(t-10) \times T_{3}(t-90) \\
& +0.3096 \times T_{4}(t-60)-0.0113 \times \hat{T}_{m, j}(t-1) \times R_{p, j}(t) \\
& +0.0033 \times \omega_{s c}(t-10) \times T_{2}(t-120) \\
& +0.0134 \times R_{p, j}(t) \times T_{2}(t-120) \\
& +0.0008 \times \omega_{s c}(t-10) \times R_{p, j}(t) \\
& +0.0043 \times \omega_{s c}(t-10) \times T_{1}(t-150) \\
& +T_{I R, \text { Error }} \pm \text { bias }
\end{aligned}
$$

In fact, the models with suitable size (i.e., from the model order and number of terms) can be selected based on the requirements of the soft sensor design.

\section{Soft sensor design}

The soft sensor design was performed by combining the dynamic process models and the feedback mechanism. The structure of the newly proposed melt temperature profile prediction soft sensor concept is shown in Figure 3. This

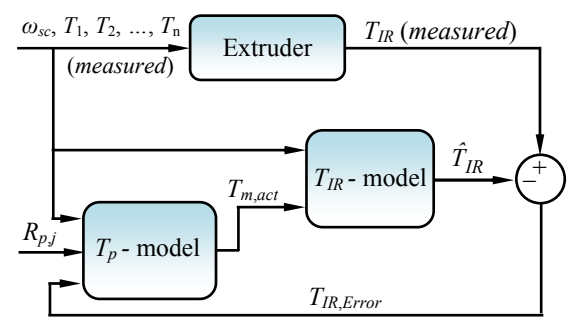

Fig. 3. The structure of the die melt temperature profile soft sensor predicts the melt temperatures of the user defined radial locations across the melt flow when the required inputs are feed into the $T_{P}$ model. The $T_{m \text {,act }}$ can be obtained by taking the average value of the $T_{P}$ model's predictions and this value can be feed into the $T_{I R}$ model together with other relevant parameters. Consequently, the $T_{I R}$ model will predict the temperature given by the IR temperature sensor and this can be compared with the actual value measured to generate the $T_{I R, \text { Error. }}$. If an error is available, it will be feed into the $T_{P}$ model together with a bias specific to the each radial position for compensating the error. These steps will be repeated throughout the process operation and hence the temperature profile across the melt flow can be predicted in real-time. The number of radial positions required to generate the melt temperature profile and the sensor's output updating frequency can be defined as suitable.

\section{Results AND Discussion}

The proposed soft sensor was implemented in MatlabSimulink to check its performance and both the measured (i.e., temperatures measured under the barrel set temperature conditions $\mathrm{A}$ and $\mathrm{B}$ given in Table I) and predicted temperature signals at $0 \mathrm{~mm}, 3.0 \mathrm{~mm}, 8.8 \mathrm{~mm}$ and $16.5 \mathrm{~mm}$ radial positions are shown in Figure 4. All figures have plotted in the same scale and the time intervals shown along the $\mathrm{X}$ axis are relevant to the times of the applied screw speed step changes. A step change of the barrel set temperatures was applied at the time of 65 minutes. Overall, the soft sensor predicts the melt temperatures at the different melt flow radial locations with good accuracy and some of the slight deviations can be seen only over a few processing conditions. To further confirm the performance/reliability of the proposed soft sensor, its responses over the disturbances were checked by adding different size of negative and positive step changes (i.e., 10, 20 and 30 units) to each individual process variable from their set value while others remained unchanged and also by applying similar types of disturbances to the feedback model. The results confirmed that the soft sensor can settle back to the normal operating conditions just after removing the applied disturbances on its input variables and the feedback model which showed good disturbance rejection ability. In fact, these experiments were carried
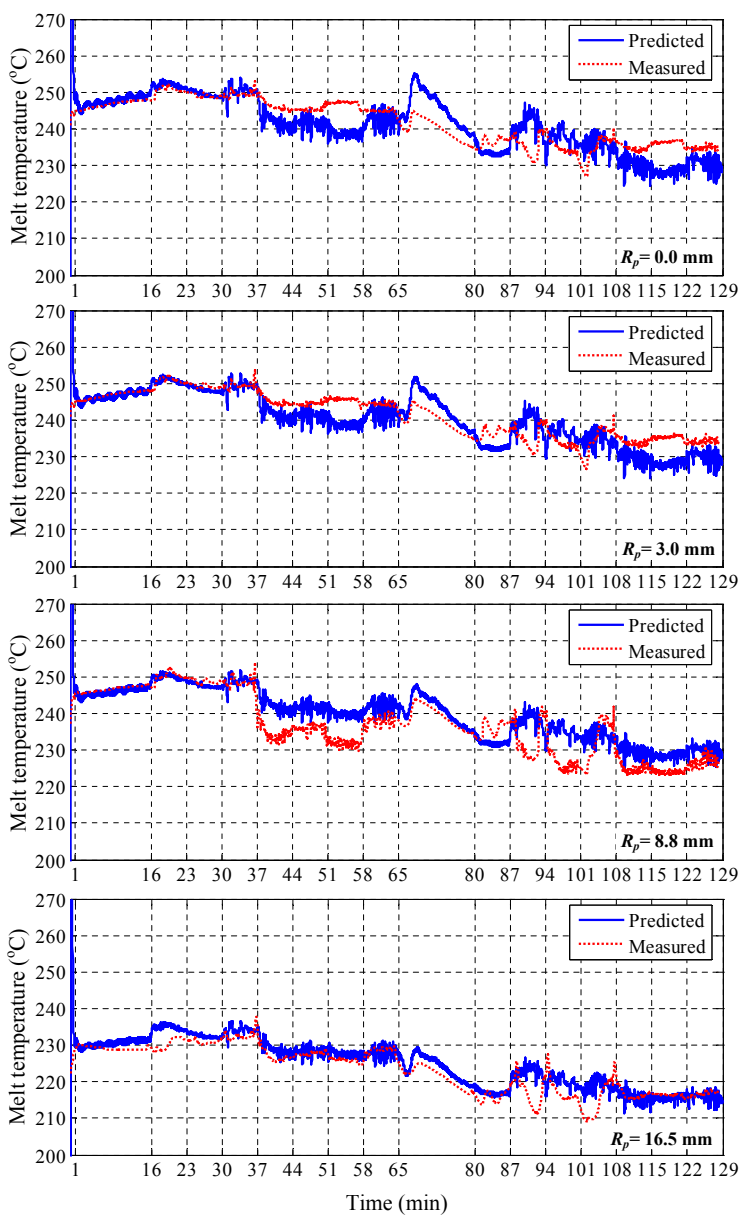

Fig. 4. Measured and predicted melt temperatures at the $0.0 \mathrm{~mm}, 3.0 \mathrm{~mm}$, $8.8 \mathrm{~mm}$ and $16.5 \mathrm{~mm}$ melt flow radial positions

out by applying frequent screw speed step changes and a large step change of the barrel set temperature (see Figure 2). However, there will be no such frequent screw speed changes in industry as the processes are usually operated at a constant temperature and speed for a long period of time. Obviously, the soft sensor may have much better performance under such constant process operating conditions. Moreover, as the newly proposed melt temperature profile prediction soft sensor showed good performance in predicting a melt temperature profile across the die melt flow, it should be used to develop a control strategy to manipulate process settings to achieve the desired average melt temperature 
across the extruder output melt flow while minimising the melt temperature variance. Some of the initial results relating to the development of a process controller incorporating this soft sensor have been presented by the author recently [33].

\section{CONCLUSIONS AND FUTURE WORK}

\section{A. Conclusions}

It was realized that the soft sensing approaches are highly useful for the processes like polymer extrusion due to the limitations of using physical sensors for making some of the important process parameters such as die melt temperature profile, melt viscosity, etc. In this study, a novel soft sensor concept was proposed to predict the temperature profile across the die melt flow in polymer extrusion. Mainly, the newly proposed soft sensor employs two dynamic process models and a feedback mechanism incorporating a physical IR temperature sensor. The soft sensor can predict the melt temperature values of a number of radial positions across the melt flow (and hence the melt temperature profile) in realtime based on five process variables. The simulation results of the proposed soft sensor confirmed that it can predicts the melt temperatures at different die radial positions with good accuracy. Moreover, the process variables required for the operation of the soft sensor can be readily measured in any practical environment to a good accuracy by using commercially available physical sensors. Therefore, this will be a promising strategy for making real-time melt temperature profile measurements in polymer extrusion which is highly difficult to perform by using a physical sensor.

\section{B. Future Work}

In future, the proposed soft sensor will be implemented in a software platform and then on an industrial scale extruder for evaluating its performance. Moreover, the possible approaches for narrowing its current limitations will be explored. Also, an attempt will be made to investigate soft sensing approaches for predicting other important parameters which are difficult to measure physically.

\section{REFERENCES}

[1] X. Shen, R. Malloy, and J. Pacini, "An experimental evaluation of melt tempearture sensors for thermopalstic extrusion," SPE ANTEC Technical Papers, pp. 918-926, 1992.

[2] C. Rauwendaal, Polymer extrusion. Hanser-Munich, 2001.

[3] C. Abeykoon, Polymer Extrusion: A Study on Thermal Monitoring Techniques and Melting Issues. Lap Lambert Publishing:Verlag, 2012.

[4] L. Fortuna, S. Graziani, A. Rizzo, and M. G. Xibilia, Soft Sensors for Monitoring and Control of Industrial Processes. Springer, 2006.

[5] H. Kaneko and K. Funatsu, "Development of high predictive soft sensor method and the application to industrial polymer processes," Asia-Pac. J. Chem. Eng., vol. 7, pp. S39-S47, 2012.

[6] P. Kadleca, B. Gabrys, and S. Strandtb, "Data-driven soft sensors in the process industry," Comput. Chem. Eng., vol. 33, pp. 795-814, 2009.

[7] L. Fortuna, S. Graziani, and M. G. Xibilia, "Comparison of softsensor design methods for industrial plants using small data sets," IEEE Trans. Instrum. Meas., vol. 58, no. 8, pp. 2444-2451, 2009.

[8] C. Abeykoon, M. McAfee, K. Li, A. L. Kelly, and E. C. Brown, "Monitoring the effect of operating conditions on melt temperature homogeneity in single-screw extrusion," SPE ANTEC Technical Papers, vol. 1, pp. 1799-1806, 2010.

[9] C. Abeykoon, M. McAfee, K. Li, P. J. Martin, and A. L. Kelly, "The inferential monitoring of screw load torque to predict process fluctuations in polymer extrusion," J. Mater. Process. Technol., vol. 211, no. 12, pp. 1907-1918, 2011.
[10] Y. Wang, W. G. Lin, H. Xu, and T. Liu, "Study on measurement of polymer orientation degree base on SVM," Adv. Mater. Res., vol. 314316, pp. 2389-2393, 2011.

[11] S. B. Chitralekha and S. L. Shah, "Application of support vector regression for developing soft sensors for nonlinear processes," The Canadian J. of Chemical Engineering, vol. 88, pp. 696-709, 2010.

[12] J. Gonzaga, L. Meleiro, C. Kiang, and R. M. Filho, "ANN-based softsensor for real-time process monitoring and control of an industrial polymerization," Comput. Chem. Eng., vol. 33, no. 1, pp. 43-49, 2009.

[13] R. Sharmin, U. Sundararaj, and Y.-J. S. S. Shah, L. V. Griend, "Inferential sensors for estimation of polymer quality parameters: Industrial application of a PLS-based soft sensor for a LDPE plant,' Chem. Eng. Sci., vol. 61, no. 19, pp. 6372-6384, 2006.

[14] M. McAfee and G. McNally, "Real-time measurement of melt viscosity in single-screw extrusion," Trans. Inst. Meas. Control, vol. 28, no. 5, pp. 481-499, 2006.

[15] J. Shi and X. Liu, "Melt index prediction by weighted least squares support vector mechanics," J. Appl. Polym. Sci., vol. 101, no. 1, pp. 285-289, 2006

[16] J. Li and X. Liu, "Melt index prediction by RBF neural network optimized with an adaptive new ant colony optimization algorithm," J. Appl. Polym. Sci., vol. 119, no. 5, pp. 3093-3100, 2010.

[17] M. Ogawa, M. Ohshima, K. Morinaga, and F. Watanabe, "Quality inferntial control of an industrial high density polyethylene process," J. Process Control, vol. 9, no. 1, pp. 51-59, 1999.

[18] P. Facco, F. Doplicher, F. Bezzo, and M. Barolo, "Moving average PLS soft sensor for online product quality estimation in an industrial batch polymerization process," J. Process Control, vol. 19, no. 3, pp. 520-529, 2009

[19] V. Noeei, S. Zhu, C. Tzoganakis, T. Duever, D. Ross, R. Clarke, P. V. Laren, and R. Pop-hey, "Model-based inferential sensing of melt flow rate in polymer compounding operations," SPE ANTEC Technical Papers, vol. 1, pp. 187-191, 2009.

[20] B. Feil, J. Abonyi, P. Pach, S. Nemeth, P. Arva, M. Nemeth, and G. Nagy, "Semi-mechanistic models for state-estimation soft sensor for polymer melt index prediction," Springer: Lecture Notes in Computer Science, vol. 3070, no. 17, pp. 1111-1117, 2004.

[21] J. Zhang, A. J. Morris, E. B. Martin, and C. Kiparissides, "Prediction of polymer quality in batch polymerisation reactors using robust neural networks," J. Appl. Polym. Sci., vol. 69, pp. 135-143, 1998.

[22] C. Abeykoon, "Modelling and control of melt tempearture in polymer extrusion," Ph.D. dissertation, Queen's University Belfast, UK, 2011.

[23] C. Abeykoon, P. J. Martin, A. L. Kelly, and E. C. Brown, "An evaluation of melt temperature sensors for polymer extrusion," Sens. Actuators, A, vol. 182, pp. 16-27, 2012.

[24] C. Abeykoon, K. Li, M. McAfee, P. J. Martin, Q. Niu, A. L. Kelly, and J. Deng, "A new model based approach for the prediction and optimisation of thermal homogeneity in single screw extrusion," Control Eng. Pract., vol. 19, no. 8, pp. 862-874, 2011.

[25] C. Abeykoon, K. Li, M. McAfee, P. J. Martin, J. Deng, and A. L. Kelly, "Modelling the effects of operating conditions on on die melt temperature homogeneity in single screw extrusion," UKACC Int. Conf. on Control, Coventry, United Kingdom, pp. 42-47, 2010.

[26] A. Wood, "Uk patent: Gb2,291,197," 1996.

[27] R. Rasid, "Effects of processing variables on the extruder characteristics," Ph.D. dissertation, UMIST, UK, 2000.

[28] A. J. Bur, M. G. Vangel, and S. C. Roth, "Fluorescence based temperature measurements and applications to real-time polymer processing," Polym. Eng. Sci., vol. 41, no. 8, pp. 1380-1389, 2001.

[29] A. L. Kelly, E. C. Brown, and P. D. Coates, "The effect of screw geometry on melt temperature profile in single screw extrusion,' Polym. Eng. Sci., vol. 46, no. 12, pp. 1706-1714, 2006.

[30] C. Abeykoon, K. Li, P. J. Martin, and A. L. Kelly, "Monitoring and modelling of the effects of process settings and screw geometry on melt pressure generation in polymer extrusion," Int. J. Syst. Control Inf. Process., vol. 1, no. 1, pp. 71-88, 2012.

[31] C. Abeykoon, K. Li, P. J. Martin, M. McAfee, and G. W. Irwin, "Extruder melt tempeature control with fuzzy logic," Proceedings of 18th IFAC World Congress, pp. 8577-8582, 2011.

[32] C. Abeykoon, M. McAfee, K. Li, P. J. Martin, J. Deng, and A. L. Kelly, "Modelling the effects of operating conditions on motor power consumption in single screw extrusion," Proceedings of LSMS 2010 and ICSEE 2010, vol. 6329, no. 2, pp. 9-20, 2010.

[33] C. Abeykoon, "A novel model-based controller for polymer extrusion," IEEE Trans. Fuzzy Syst., vol. 22, no. 6, 2014. 